\title{
Aplikasi Penghubung Guru dan Orang Tua: e-Counseling
}

\author{
Studi Kasus SMP Negeri 89 Jakarta
}

\author{
Tyas Agustini ${ }^{1}$, Abdi Wahab ${ }^{2}$ \\ ${ }^{1,2}$ Sistem Informasi, Fakultas Ilmu Komputer, Universitas Mercu Buana, Jakarta, Indonesia \\ ${ }^{1}$ tyasssags075@gmail.com \\ 2 abdi.wahab@mercubuana.ac.ic
}

Diterima 22 Agustus 2020

Disetujui 19 November 2020

\begin{abstract}
SMP Negeri 89 is the first formal secondary education institution used for teaching and learning activities. There are many ways to improve students ' performance and discipline in one way by engaging teachers and parents to periodically monitor the activities of students in school and at home using a stillongoing contact book. Manually causing constraints in the form of students to forge signatures of parents and books often left at home by students not brought back to school. The purpose of this research is to create a student activity Monitoring application in school or at home. In building this system the author uses Waterfall method. While for assisting in system analysis and design we use Unified Modeling Language (UML) and Waterfall method for developing the application. The Results from this research in SMP Negeri 89 Jakarta can be concluded that with Website-based Teacher and Parental Liaison Applications can facilitate teachers and parents in monitoring students.
\end{abstract}

Index Terms - counseling, SMP, teacher and parents

\section{Pendahuluan}

Sekolah Menengah Pertama merupakan pendidikan formal pada jenjang pendidikan dasar. Pendidikan dan pembelajaran di tingkat SMP memberikan penekanan peletakan pondasi dalam menyiapkan generasi agar menjadi manusia yang mampu menghadapi era yang semakin berat. Menurut Undang-Undang Sistem Pendidikan Nasional no 20 tahun 2003 pasal 17 pendidikan dasar disebutkan bahwa pendidikan dasar terdiri dari SD (Sekolah Dasar)/sederajat dan SMP (Sekolah Menengah Pertama) /sederajat.

SMP Negeri 89 pada awalnya adalah perubahan dan perpindahan SMP LKPMDC, yang berlokasi di Rumah Bedeng Arhanud (1966 - 1968), lalu pindah ke Tanjung Duren Barat IV (1969). Berikutnya berubah menjadi SMP Persiapan Negeri (1970). Selanjutnya menjadi SMP Negeri 89 Jakarta (20 Oktober 1971). SMP Negeri 89 Jakarta juga Sekolah Standar Nasional (SSN) di Jakarta Barat dan memperoleh Akreditasi A yang sekarang berlokasi di Jl. Tanjung Duren Barat 4,
Kelurahan Tanjung Duren Utara, Kecamatan Grogol Petamburan Jakarta Barat.

Selama ini penghubung guru dan orang tua masih dilakukan secara manual dengan menggunakan buku yang diberi nama buku penghubung, buku penghubung merupakan sebuah buku yang memiliki format tertentu. Format pada buku penghubung terdiri dari nomor, waktu yakni hari/tanggal, kasus/prestasi, dan keterangan yang berisi tanda tangan guru dan orang tua. Dikarenakan sering terjadinya kehilangan buku penghubung, pemalsuan tanda tangan orang tua oleh siswa dan buku sering tertinggal di rumah oleh siswa tidak dibawanya kembali ke sekolah.

Buku penghubung yang ada di sekolah selama ini merupakan media yang dapat membuat orang tua ikut berperan aktif dalam pendidikan anaknya. Bagaimana pun, peran orang tua dalam pendidikan seorang anak sangatlah penting, sesuai dengan visi dan misi dari SMP Negeri 89, bahwa peran orang tua dalam membangun jati diri siswa sangatlah diperlukan. Kemudian permasalahan penyampaian informasi yang akurat dan aktual merupakan komoditas yang krusial bagi orang tua terkait permaslahan dan perkembangan anaknya di sekolah.

Oleh karena itu, berdasarkan pada hal-hal di atas, maka penelitian ini akan mencoba membuat Aplikasi Penghubung Guru dan Orang Tua untuk menjembatani antara orang tua dengan pihak sekolah terutama guru. Selain itu, orang tua juga akan dipermudah dalam memantau permasalahan yang terjadi di sekolah untuk anak-anak mereka.

Beberapa penelitian terkait dengan media penghubung antara orang tua dan guru dilakukan pada [1], [3], [5], [6], [9], [11], dan [12]. Pada penelitian sebelumnya, terdapat fitur SMS sebagai notifikasi, untuk aplikasi "E-Counseling" akan digunakan email sebagai notifikasi. Sedangkan pada [10] sebagai rujukan untuk aplikasi monitoring siswa di tingkat SMA. 


\section{TINJAUAN PUSTAKA}

\section{A. Laporan}

Laporan adalah alat komunikasi tertulis yang memuat hasil pengolahan data dan informasi serta memberikan kesimpulan atau rekomendasi atas fakta fakta atau keadaan - keadaan yang telah diselidiki sebelumnya. Laporan sangat penting artinya bagi seorang pemimpin karena merupakan salah satu alat untuk melaksanakan kegiatan dalam perencanaan, pengendalian, pengawasan, dan pengampilan keputusan[1].

\section{B. Konsep Buku Penghubung}

Kerja sama antara orangtua dengan sekolah sangatlah penting dilakukan untuk menunjang perkembangan anak yang lebih baik khususnya di bidang akademiknya. Adapun kerja sama tersebut diaplikasikan melalui buku penghubung. Buku penghubung adalah pemanfaatan aktivitas pendidikan peserta didik yang dilakukan oleh pendidik dan orangtua melalui buku kegiatan harian. Menurut Dance, komunikasi ditinjau dari segi psikologi behaviorisme adalah mengungkapkan perasaan melalui lambang verbal sebagai stimulus untuk menimbulkan respon [2].

\section{Metode Penelitian}

Pada sub bab ini, akan dibahas metode penelitian yang akan digunakan dalam penelitian ini.

\section{A. Lokasi Penelitian}

Lokasi penelitian bertempat di SMP Negeri 89 Jakarta, yang beralamat di Jl. Tanjung Duren Barat 4, Kelurahan Tanjung Duren Utara, Kecamatan Grogol Petamburan Jakarta Barat, 11470.

\section{B. Teknik Pengumpulan Data}

Metode yang digunakan dalam teknik pengumpulan data kualitatif dengan penyusunan laporan untuk penghubung guru dan orang tua, diantaranya:

- Observasi

- Wawancara

- Studi literatur

\section{Diagram Alir Penelitian}

Alir penelitian yang dilakukan pada penelitian ini mengikuti pendekatan dari metode pengembangan perangkat lunak Waterfall [13]. Gambar 1 menampilkan alir dari penelitian yang dilakukan pada penelitian ini.

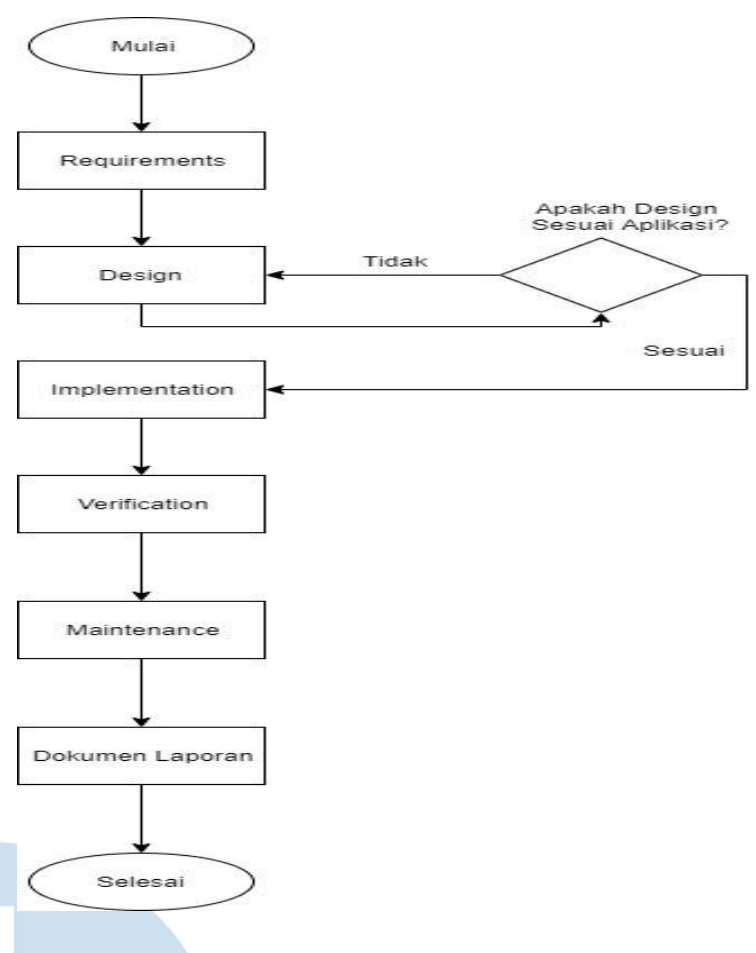

Gambar 1. Diagram alir penelitian

\section{HASIL DAN PEMBAHASAN}

A. Analisa Sistem Berjalan

Analisa sistem berjalan adalah kajian yang dilakukan untuk mengetahui urutan pelaksanaan dalam suatu organisasi yang bertujuan untuk mendapatkan keuntungan dengan menggunakan berbagai sumber daya. Analisa sistem berjalan umumnya melibatkan pemetaan proses di dalamnya hingga tingkatan aktivitas atau kegiatan. Gambar 2 menunjukkan proses penghubung antara orang tua dan guru yang terjadi saat ini di SMP Negeri 89. 


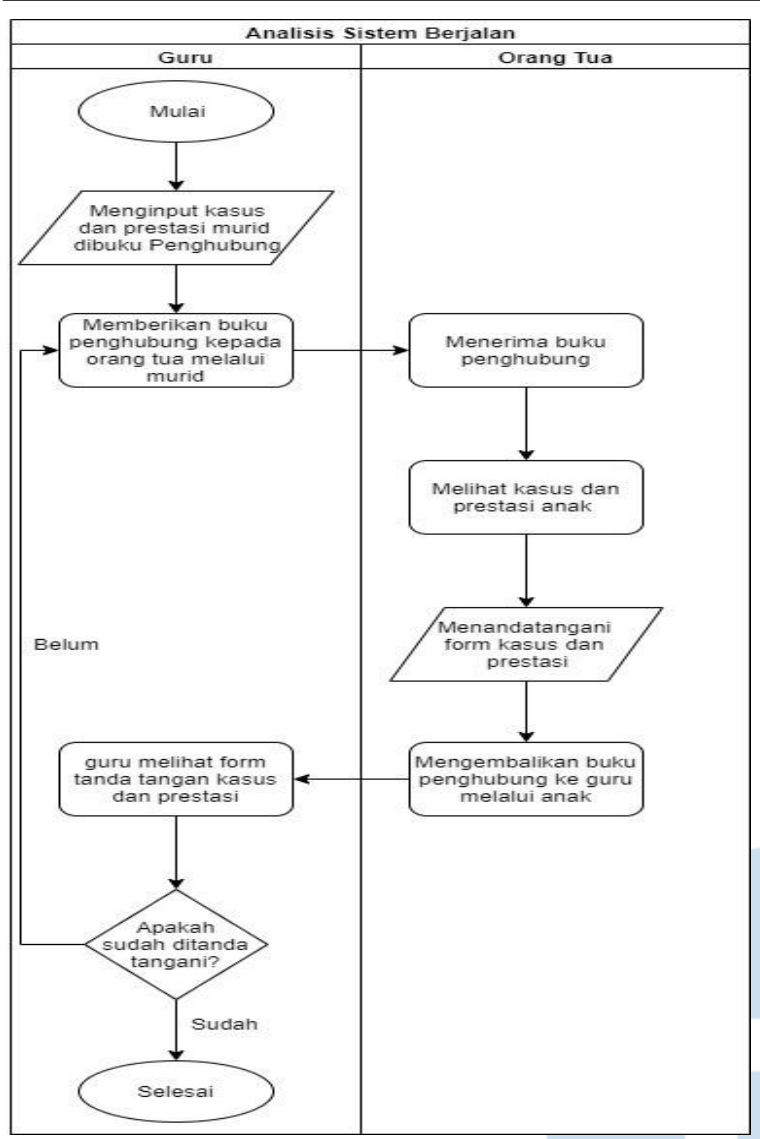

Gambar 2. Analisa sistem berjalan

\section{B. Identifikasi Masalah}

Untuk menentukan masalah pada penelitian ini, digunakan analisa PIECES (Performance, Information, Economy, Control, Efficiency and Service) [14]. Aspek-aspek yang ada di dalam PIECES dijelaskan pada Tabel 1.

Tabel 1. Identifikasi masalah dengan PIECES

\begin{tabular}{|c|c|c|}
\hline Kriteria & Masalah & Solusi \\
\hline Performance & $\begin{array}{l}\text { Data disimpan } \\
\text { masih manual } \\
\text { sehingga jika } \\
\text { terjadi } \\
\text { kehilangan dan } \\
\text { kerusakan buku } \\
\text { maka data yang } \\
\text { disimpan akan } \\
\text { hilang } \\
\end{array}$ & $\begin{array}{l}\text { Penyimpanan data } \\
\text { menggunakan } \\
\text { database, sehingga } \\
\text { apabila kehilangan } \\
\text { data, sekolah } \\
\text { masih memiliki } \\
\text { backup data yang } \\
\text { disimpan di dalam } \\
\text { database }\end{array}$ \\
\hline Information & $\begin{array}{l}\text { Informasi } \\
\text { monitoring lama } \\
\text { tersampaikan } \\
\text { kepada orang } \\
\text { tua }\end{array}$ & $\begin{array}{l}\text { Informasi } \\
\text { monitoring cepat } \\
\text { sampai ke orang } \\
\text { tua karena orang } \\
\text { tua dapat melihat } \\
\text { dan mengakses } \\
\text { dimanapun }\end{array}$ \\
\hline
\end{tabular}

\begin{tabular}{|c|c|c|}
\hline Economic & $\begin{array}{l}\text { Sekolah banyak } \\
\text { mengeluarkan } \\
\text { dana untuk } \\
\text { membeli buku } \\
\text { penghubung } \\
\text { untuk setiap } \\
\text { murid }\end{array}$ & $\begin{array}{l}\text { Adanya sebuah } \\
\text { aplikasi berbasis } \\
\text { web ini } \\
\text { menjadikan } \\
\text { perusahaan } \\
\text { menghemat } \\
\text { pengeluaran } \\
\text { membeli buku } \\
\text { penghubung untuk } \\
\text { setiap murid }\end{array}$ \\
\hline Control & $\begin{array}{l}\text { Dikarenakan } \\
\text { masih } \\
\text { menggunakan } \\
\text { pembukuan } \\
\text { secara manual } \\
\text { sehingga tidak } \\
\text { ada batasan } \\
\text { pengaksesan } \\
\text { data oleh } \\
\text { siapapun yang } \\
\text { menemukan } \\
\text { atau } \\
\text { mendapatkan } \\
\text { data tersebut. }\end{array}$ & $\begin{array}{l}\text { Adanya menu } \\
\text { login membuat } \\
\text { Orang Tua yang } \\
\text { tidak bersangkutan } \\
\text { tidak dapat } \\
\text { mengakses } \\
\text { kedalam sistem. }\end{array}$ \\
\hline Efficiency & $\begin{array}{l}\text { Orang tua tidak } \\
\text { dapat merespon } \\
\text { laporan yang } \\
\text { diberikan oleh } \\
\text { guru }\end{array}$ & $\begin{array}{l}\text { Adanya menu } \\
\text { pesan sehingga } \\
\text { dapat membantu } \\
\text { guru dan orang tua } \\
\text { berkomunikasi } \\
\text { langsung di dalam } \\
\text { web e-counseling. }\end{array}$ \\
\hline Services & $\begin{array}{l}\text { Input data } \\
\text { seperti tanggal, } \\
\text { nama murid, } \\
\text { nilai harus } \\
\text { ditulis satu } \\
\text { persatu }\end{array}$ & $\begin{array}{l}\text { Input data mudah } \\
\text { karena di sistem } \\
\text { membantu } \\
\text { menginput data } \\
\text { otomatis }\end{array}$ \\
\hline
\end{tabular}

Berdasarkan hasil dari identifikasi masalah di Tabel 1, SMP Negeri 89 Jakarta memerlukan sebuah sistem penghubung antara orang tua dan guru, untuk lebih membantu dalam proses komunikasi antara mereka.

\section{Perancangan Sistem}

Perancangan sistem pada penelitian ini menggunakan UML 2.0. Diagram yang digunakan antara lain USE case, Activity Diagram, Sequence Diagram, dan Class Diagram. Untuk Activity dan Sequence Diagram, tidak akan dibahas secara keseluruhan, akan tetapi dipilih dari fitur yang pokok pada penelitian ini.

\section{- USE Case Diagram}

USE Case Diagram dari aplikasi yang akan dibangun akan dipaparkan dalam Gambar 3. 


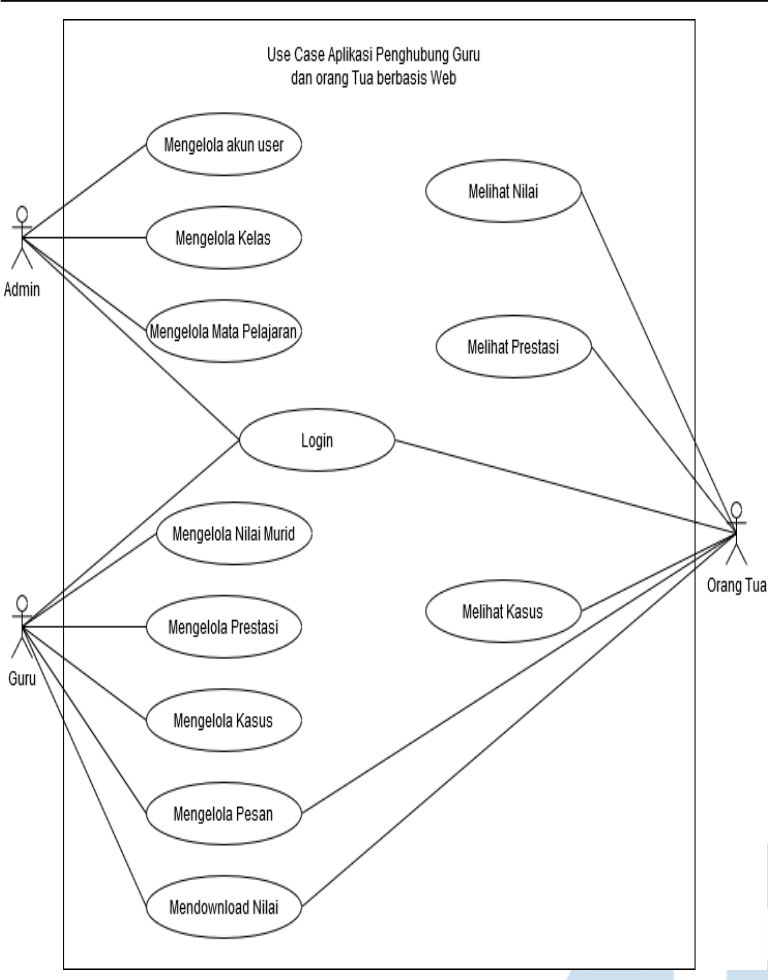

Gambar 3. USE case diagram aplikasi penghubung guru dan orang tua

\section{- Activity Diagram}

Activity diagram yang akan ditampilkan disini adalah activity diagram untuk mengelola kasus. Permasalahan ini yang sering terjadi di banyak sekolah, dan terkadang pihak orang tua siswa ikut terlibat. Sehingga fitur ini harus dapat diakses oleh guru dan orang tua.

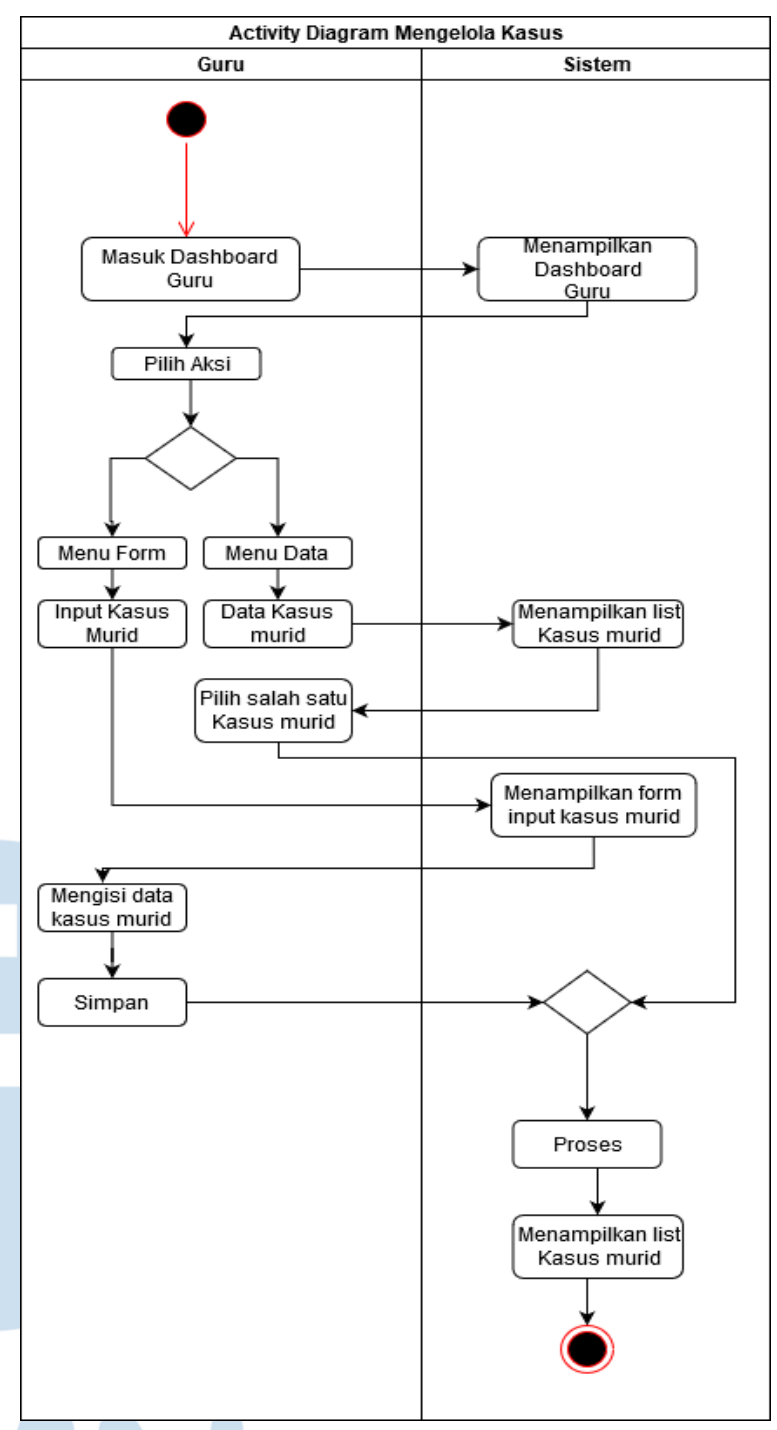

Gambar 4. Activity diagram mengelola kasus

Sedangkan untuk orang tua, mereka hanya bisa melihat kasus yang terjadi untuk anak mereka. Gambar 5 menggambarkan aktivitas melihat kasus tersebut. 


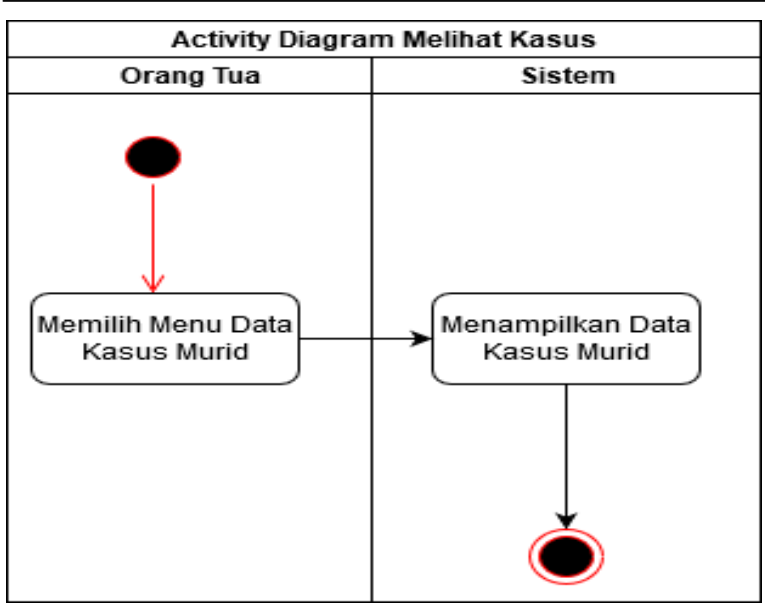

Gambar 5. Activity diagram melihat kasus

\section{- Sequence Diagram}

Sequence diagram yang akan ditampilkan adalah sequence diagram untuk mengelola kasus, dan digambarkan di Gambar 6.

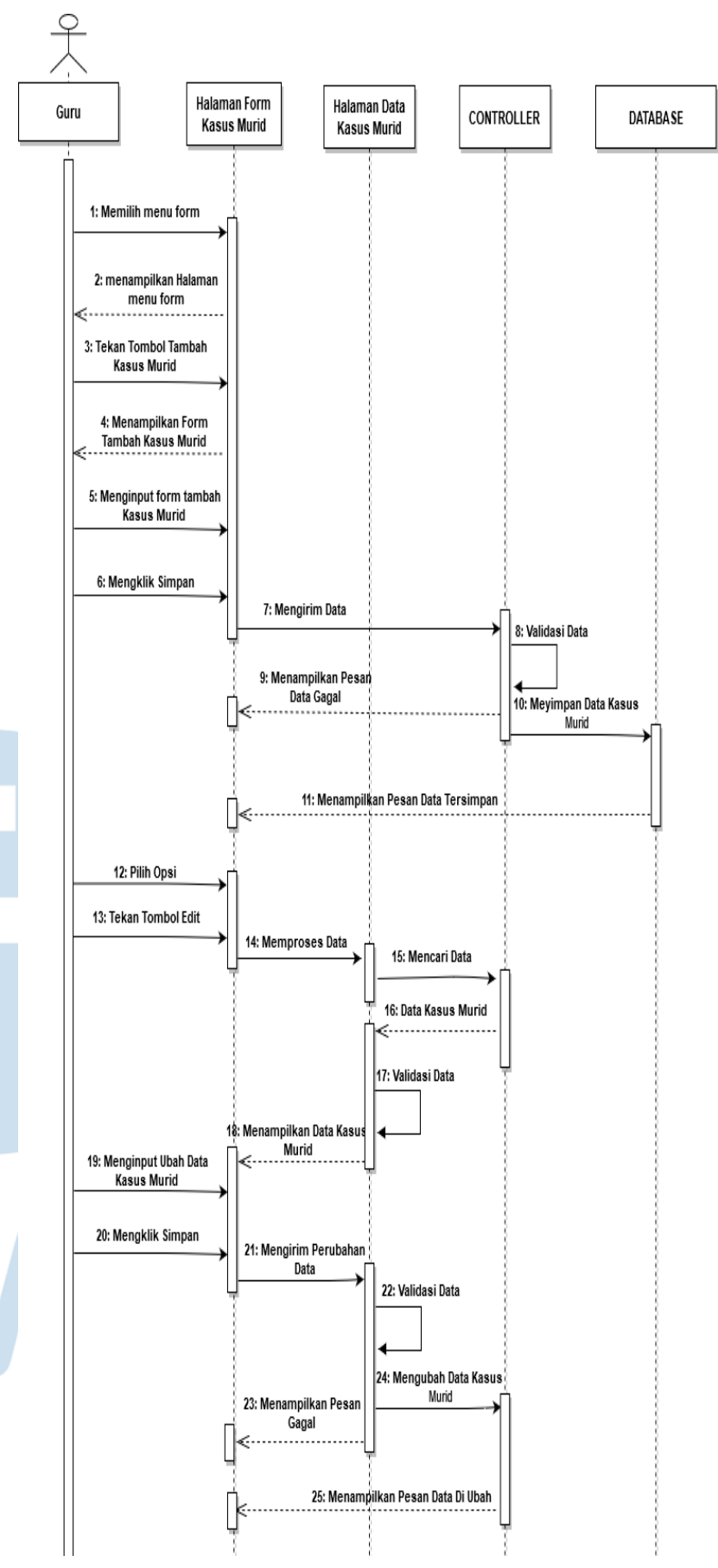

Gambar 6. Sequence diagram mengelola kasus

Sedangkan untuk orang tua melihat kasus, sequence diagramnya digambarkan pada Gambar 7. 


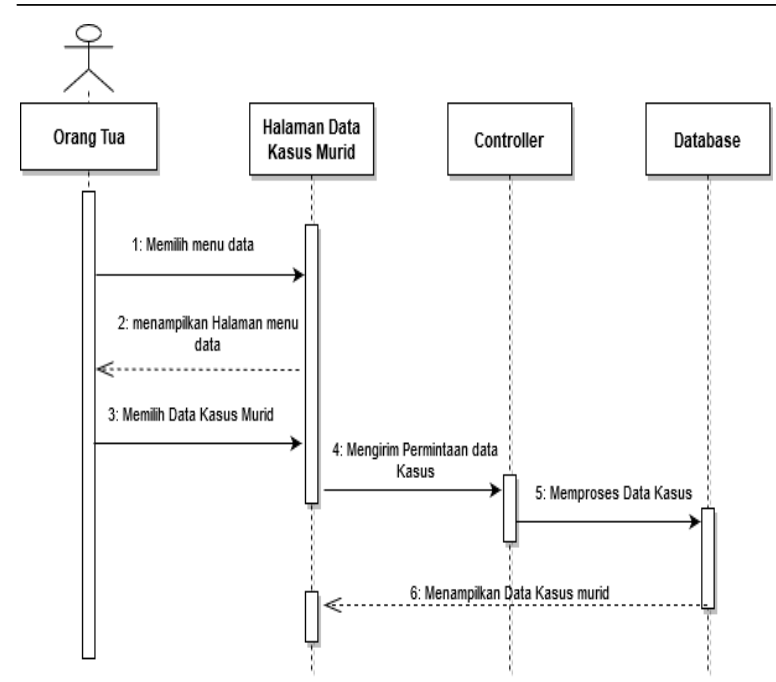

Gambar 7. Sequence diagram melihat kasus

\section{- Class Diagram}

Class diagram pada penelitian ini digunakan untuk menggambarkan objek yang akan digunakan pada aplikasi yang akan dibangun. Gambar 8 menggambarkan class diagram pada aplikasi penghubung guru dan orang tua.

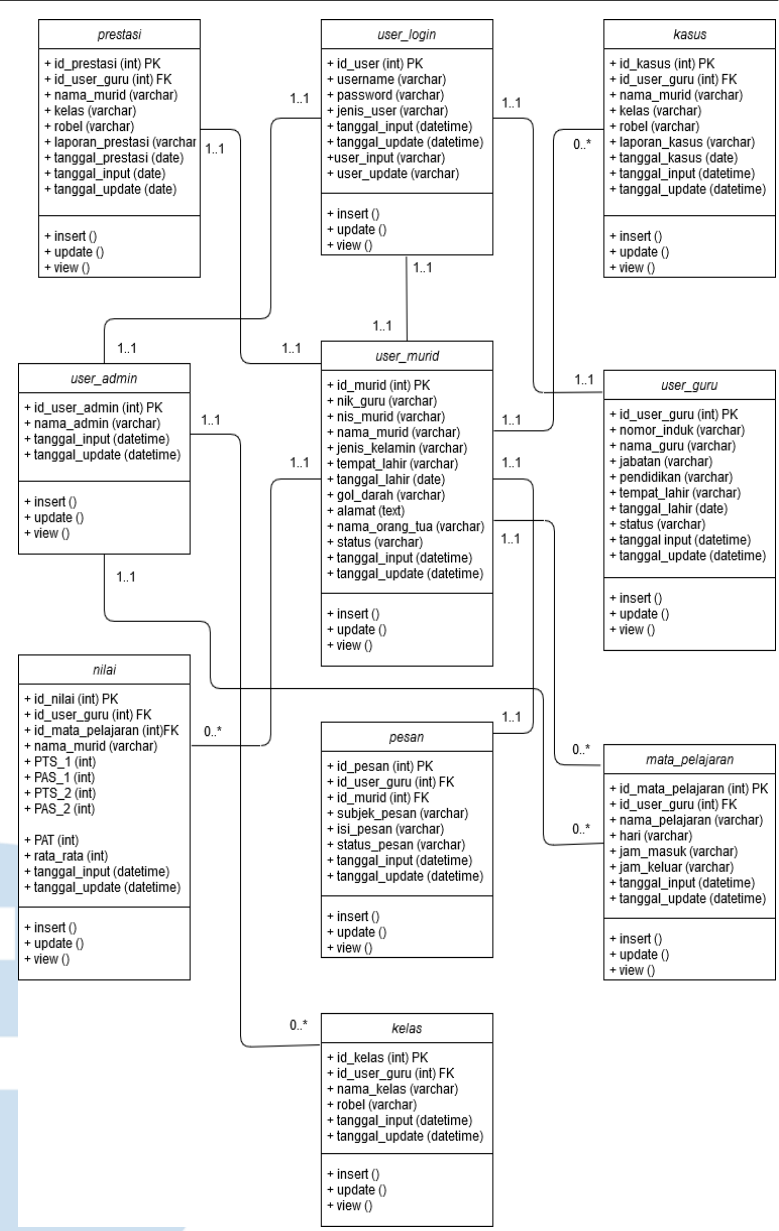

Gambar 8. Class diagram aplikasi penghubung guru dan orang tua

Pada sistem ini, orang tua akan menggunakan akun murid untuk mengakses aplikasi, hal ini dilakukan agar orang tua tidak perlu untuk melakukan registrasi diawal dari penggunaan aplikasi ini.

\section{Perancangan Antar Muka}

Beberapa gambar di bawah ini menunjukkan rancangan antar muka dari aplikasi penghubung guru dan orang tua. 


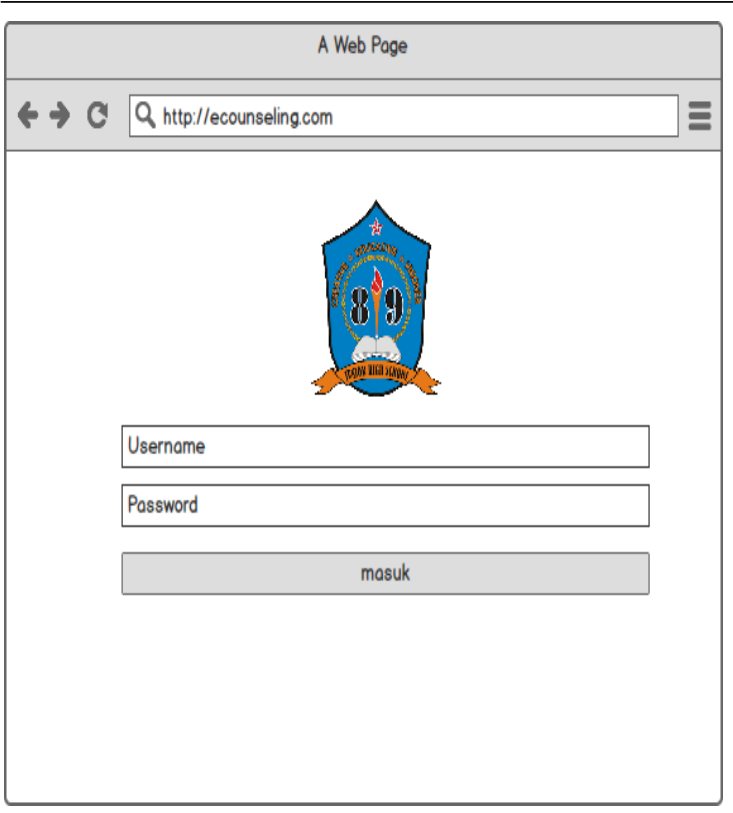

Gambar 9. Rancangan halaman login

\begin{tabular}{|c|c|c|c|}
\hline \multicolumn{4}{|c|}{ A Web Poge } \\
\hline \multicolumn{2}{|c|}{$\leftrightarrow \rightarrow C Q_{\text {hitpip/lecounselingcom }}$} & & $=$ \\
\hline Doshboord & \multirow{11}{*}{ 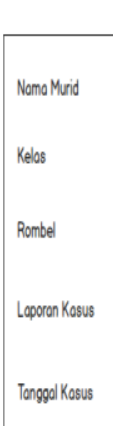 } & & Dosilbourd > Home \\
\hline Home & & & \\
\hline Forms & & Namo Murid & $\checkmark$ \\
\hline hout Nia Mund & & & \\
\hline Input Prestosi Munid & & Kelos & 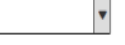 \\
\hline Inoul Pesen Mrid & & & \\
\hline Inout Kossus Murid & & Rombel & - \\
\hline \multirow{2}{*}{\begin{tabular}{|l} 
Dato \\
Doto Noi Murid
\end{tabular}} & & & \\
\hline & & Leporon Kossus & \\
\hline Doto Prestosis Murd & & & \\
\hline Dato Peseson Mrid & & Tongege Kossus & \\
\hline \multirow[t]{2}{*}{ Dato Kossus Mund } & & 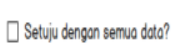 & \\
\hline & & Tomboh & \\
\hline
\end{tabular}

Gambar 10. Rancangan halaman input kasus murid

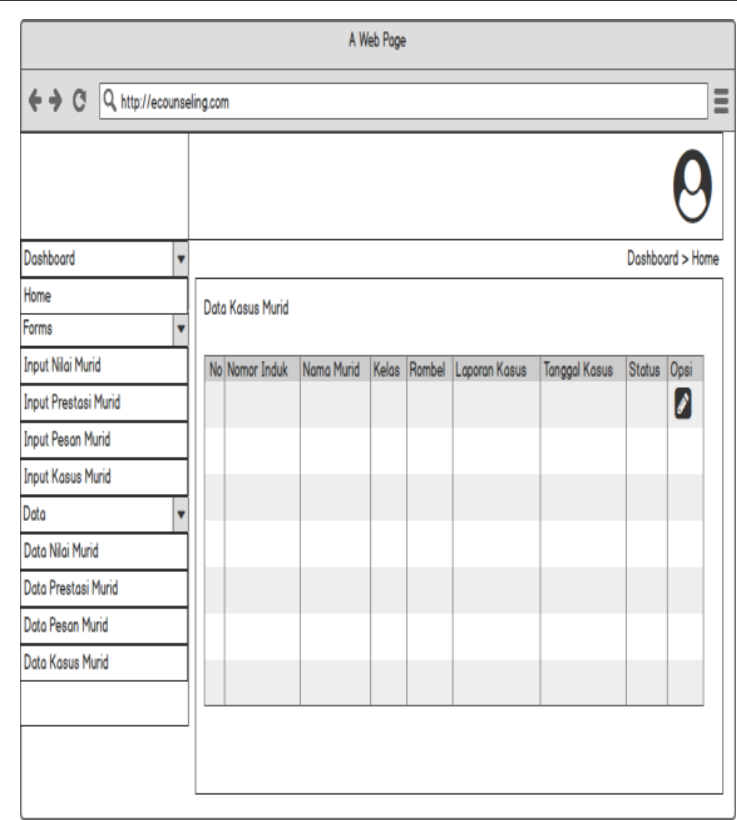

Gambar 11. Rancangan halaman data kasus murid

\section{E. Implementasi Hasil Keluaran}

Pada tahap ini aplikasi telah selesai dibangun dan sudah sesuai dengan proses bisnis digambarkan dari langkah awal hingga langkah akhir. Pada implementasi ini akan di jelaskan beberapa tampilan dan keterangan fungsinya:

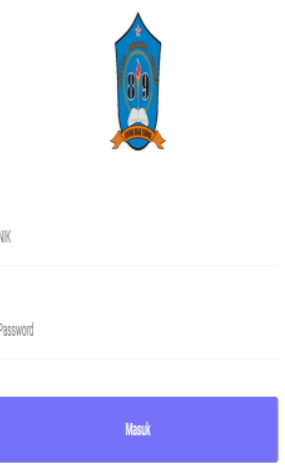

Coxpight to jys hastini

Gambar 12. Halaman login 


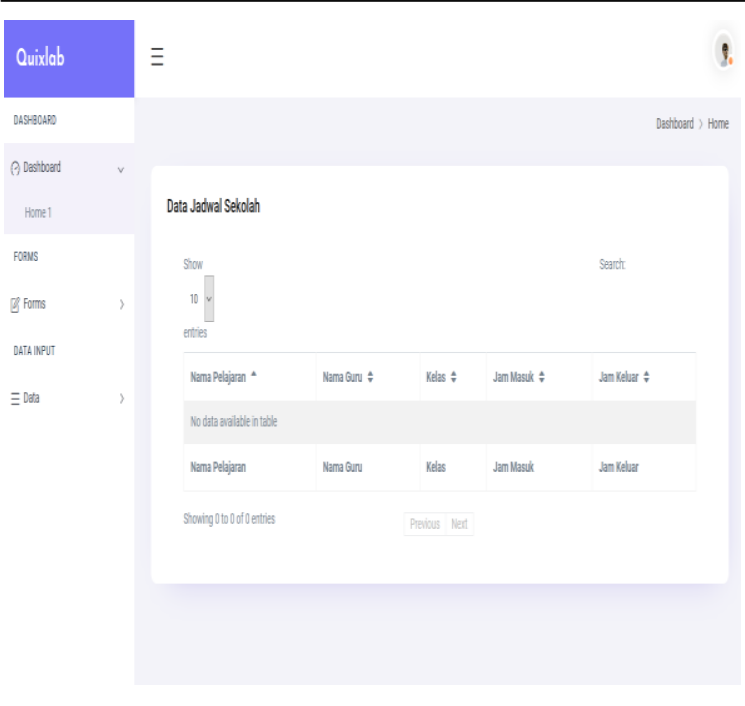

Gambar 13. Halaman beranda

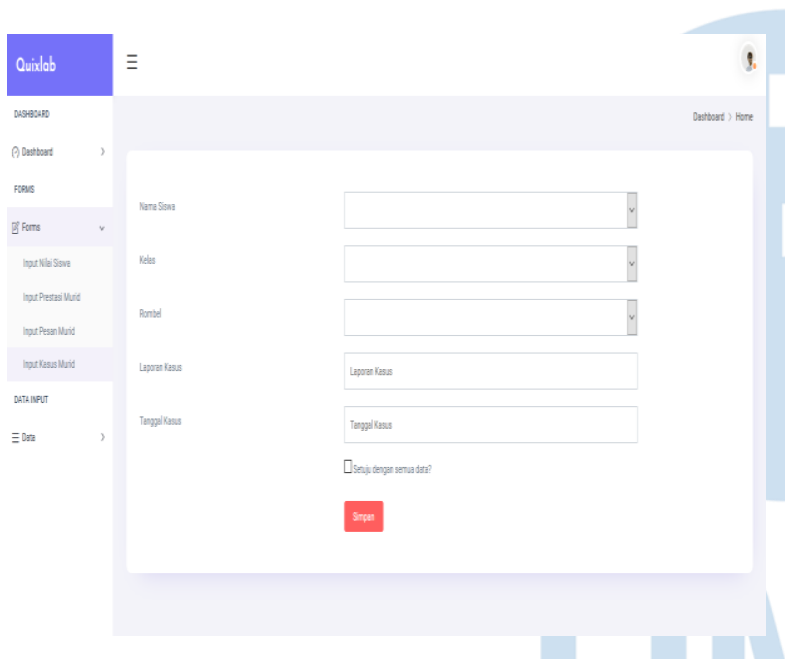

Gambar 14. Halaman input data kasus murid

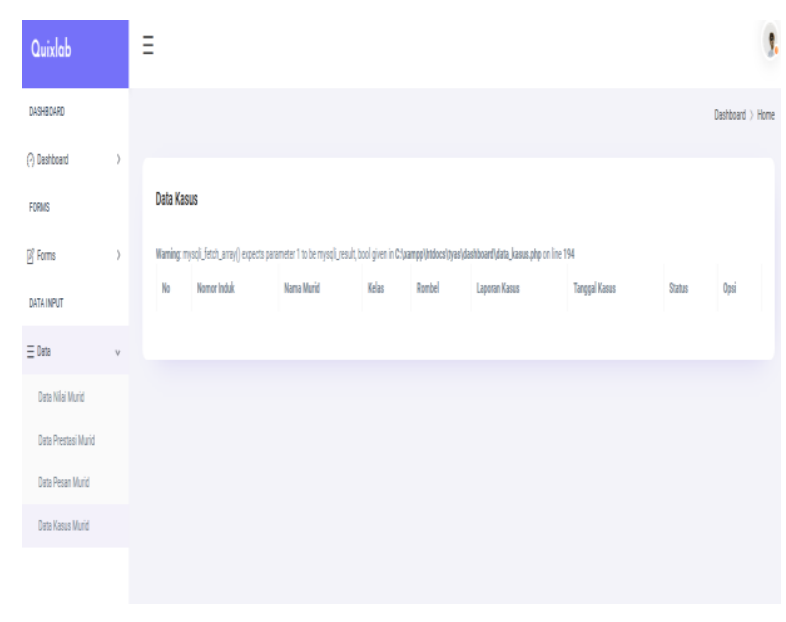

Gambar 15. Halaman data kasus murid

\section{F. Perancangan Masukkan}

Perancangan masukkan yang telah dibuat pada penelitian ini ditunjukkan pada Tabel 2.

Tabel 2. Perancangan Masukan

\begin{tabular}{|c|c|c|}
\hline Aktor & Nama Masukan & Sumber \\
\hline User & Form Login & Halaman Login \\
\hline Admin & $\begin{array}{l}\text { Form Tambah Akun } \\
\text { Guru }\end{array}$ & Halaman Guru \\
\hline Admin & Form Ubah Akun Guru & Halaman Guru \\
\hline Admin & $\begin{array}{l}\text { Form Tambah Akun } \\
\text { Murid }\end{array}$ & Halaman Murid \\
\hline Admin & $\begin{array}{l}\text { Form Ubah Akun } \\
\text { Murid }\end{array}$ & Halaman Murid \\
\hline Admin & Form Tambah Kelas & Halaman Kelas \\
\hline Admin & Form Ubah Kelas & Halaman Kelas \\
\hline Admin & $\begin{array}{l}\text { Form Tambah Mata } \\
\text { Pelajaran }\end{array}$ & $\begin{array}{l}\text { Halaman Mata } \\
\text { Pelajaran }\end{array}$ \\
\hline Admin & $\begin{array}{l}\text { Form Ubah Mata } \\
\text { Pelajaran }\end{array}$ & $\begin{array}{l}\text { Halaman Mata } \\
\text { Pelajaran }\end{array}$ \\
\hline Guru & Form Input Nilai Murid & $\begin{array}{l}\text { Halaman Nilai } \\
\text { Murid }\end{array}$ \\
\hline Guru & Form Ubah Nilai Murid & $\begin{array}{l}\text { Halaman Nilai } \\
\text { Murid }\end{array}$ \\
\hline Guru & $\begin{array}{l}\text { Form Input Prestasi } \\
\text { Murid }\end{array}$ & $\begin{array}{l}\text { Halaman Prestas } \\
\text { Murid }\end{array}$ \\
\hline Guru & $\begin{array}{l}\text { Form Ubah Prestasi } \\
\text { Murid }\end{array}$ & $\begin{array}{l}\text { Halaman Prestas } \\
\text { Murid }\end{array}$ \\
\hline Guru & $\begin{array}{l}\text { Form Input Pesan } \\
\text { Murid }\end{array}$ & $\begin{array}{l}\text { Halaman Pesan } \\
\text { Murid }\end{array}$ \\
\hline Guru & $\begin{array}{l}\text { Form Input Kasus } \\
\text { Murid }\end{array}$ & $\begin{array}{l}\text { Halaman Kasus } \\
\text { Murid }\end{array}$ \\
\hline Guru & Form Ubah Kasus & $\begin{array}{l}\text { Halaman Kasus } \\
\text { Murid }\end{array}$ \\
\hline $\begin{array}{l}\text { Orang } \\
\text { Tua }\end{array}$ & Form Input Pesan & Halaman Pesan \\
\hline
\end{tabular}

\section{G. Perancangan Keluaran}

Perancangan keluaran dari aplikasi ini dijelaskan pada Tabel 3, yang berisi query dari keluaran aplikasi.

Tabel 3. Perancangan Keluaran

\begin{tabular}{|l|l|}
\hline \multicolumn{1}{|c|}{ Nama Keluaran } & \multicolumn{1}{c|}{ Basis Data } \\
\hline $\begin{array}{l}\text { Menampilkan } \\
\text { halaman data guru }\end{array}$ & SELECT * FORM user_guru \\
\hline $\begin{array}{l}\text { Menampilkan } \\
\text { halaman data murid }\end{array}$ & SELECT * FORM user_murid \\
\hline $\begin{array}{l}\text { Menampilkan } \\
\text { halaman data kelas }\end{array}$ & $\begin{array}{l}\text { SELECT * FORM kelas a INNER } \\
\text { JOIN user_guru b on a.id = b.id }\end{array}$ \\
\hline $\begin{array}{l}\text { Menampilkan } \\
\text { halaman data mata } \\
\text { pelajaran }\end{array}$ & $\begin{array}{l}\text { SELECT * FORM mata_pelajaran } \\
\text { a INNER JOIN user_guru b on a.id } \\
\text { =b.id }\end{array}$ \\
\hline $\begin{array}{l}\text { Menampilkan data } \\
\text { nilai murid }\end{array}$ & $\begin{array}{l}\text { SELECT * FORM nilai a INNER } \\
\text { JOIN user_guru b on a.id = b.id } \\
\text { Join mata_pelajaran c on b.id = c.id }\end{array}$ \\
\hline $\begin{array}{l}\text { Menampilkan data } \\
\text { Prestasi murid }\end{array}$ & $\begin{array}{l}\text { SELECT * FORM Prestasi a } \\
\text { INNER JOIN user_guru b on a.id }= \\
\text { b.id }\end{array}$ \\
\hline
\end{tabular}




\begin{tabular}{|c|c|}
\hline $\begin{array}{l}\text { Menampilkan data } \\
\text { Pesan Murid }\end{array}$ & $\begin{array}{l}\text { SELECT } * \text { FORM pesan a INNER } \\
\text { JOIN user_guru b on a.id }=\text { b.id } \\
\text { Join user_murid } c \text { on } b . i d=c . i d\end{array}$ \\
\hline $\begin{array}{l}\text { Menampilkan data } \\
\text { Kasus Murid }\end{array}$ & $\begin{array}{l}\text { SELECT * FORM kasus a INNER } \\
\text { JOIN user_guru b on a.id = b.id }\end{array}$ \\
\hline $\begin{array}{l}\text { Menambah data } \\
\text { guru }\end{array}$ & $\begin{array}{l}\text { INSERT INTO user_guru } \\
\text { ('id_user_guru','nomor_induk','nam } \\
\text { a_guru','jabatan','pendidikan','tempa } \\
\text { t_lahir','tanggal_lahir','status','tangg } \\
\text { al_update','tanggal_update') } \\
\text { VALUES (' ',',',',',',', ',', ',', ',' ',', ',' ' ') }\end{array}$ \\
\hline $\begin{array}{l}\text { Menambah data } \\
\text { murid }\end{array}$ & $\begin{array}{l}\text { INSERT INTO user_murid } \\
\text { ('id_murid', 'nik_guru', 'nis_murid', } \\
\text { 'nama_murid', 'jenis_kelamin', } \\
\text { 'tempat_lahir', 'tanggal_lahir', } \\
\text { 'gol_darah', 'alamat', } \\
\text { 'nama_orang_tua') VALUES (' ',' ',' } \\
\text { ',',', ',' ',', ',',',',', ') }\end{array}$ \\
\hline $\begin{array}{l}\text { Menambah data } \\
\text { kelas }\end{array}$ & $\begin{array}{l}\text { INSERT INTO kelas ('id_kelas', } \\
\text { 'nama_kelas', 'robel') VALUES (' ',' } \\
\text { ',',',') }\end{array}$ \\
\hline $\begin{array}{l}\text { Menambah mata } \\
\text { pelajaran }\end{array}$ & $\begin{array}{l}\text { INSERT INTO mata_pelajaran } \\
\text { ('id_mata_pelajaran', } \\
\text { 'nama_pelajaran', 'hari', } \\
\text { 'jam_masuk', 'jam_keluar') } \\
\text { VALUES (' ',' ',' ',' ',' ') }\end{array}$ \\
\hline $\begin{array}{l}\text { Menambah nilai } \\
\text { murid }\end{array}$ & $\begin{array}{l}\text { INSERT INTO nilai ('id_nilai', } \\
\text { 'nama_murid', 'PTS_1', 'PAS_1', } \\
\text { 'PTS_2', 'PAS_2') VALUES (' ',',', } \\
\text { ',',',',', ') }\end{array}$ \\
\hline $\begin{array}{l}\text { Menambah Prestasi } \\
\text { murid }\end{array}$ & $\begin{array}{l}\text { INSERT INTO prestasi } \\
\text { ('id_prestasi', 'nama_murid', 'kelas', } \\
\text { 'robel', 'laporan_prestasi', } \\
\text { 'tanggal_prestasi') VALUES (' ', ', ', } \\
\text { ',',',',', ') }\end{array}$ \\
\hline $\begin{array}{l}\text { Menambah data } \\
\text { Pesan Murid }\end{array}$ & $\begin{array}{l}\text { INSERT INTO pesan ('id_pesan', } \\
\text { 'subjek_pesan', 'isi_pesan') } \\
\text { VALUES (' ',' ',' ') }\end{array}$ \\
\hline $\begin{array}{l}\text { Menambah data } \\
\text { Kasus Murid }\end{array}$ & $\begin{array}{l}\text { INSERT INTO kasus ('id_kasus', } \\
\text { 'nama_murid', 'kelas', 'robel', } \\
\text { 'laporan_kasus', 'tanggal_kasus') } \\
\text { VALUES (' ',' ',' ',',',' ',' ') }\end{array}$ \\
\hline $\begin{array}{l}\text { Mengubah data } \\
\text { guru }\end{array}$ & $\begin{array}{l}\text { UPDATE user_guru SET } \\
\text { id_user_guru = 'id_user_guru' } \\
\text { WHERE nomor_induk = } \\
\text { 'nomor_induk' OR nama_guru } \\
\text { ='nama_guru' OR jabatan = } \\
\text { 'jabatan' OR pendidikan = } \\
\text { 'pendidikan' }\end{array}$ \\
\hline $\begin{array}{l}\text { Mengubah data } \\
\text { murid }\end{array}$ & $\begin{array}{l}\text { UPDATE user_murid SET } \\
\text { id_murid = 'id_murid' WHERE } \\
\text { nik_guru = 'nik_guru' OR } \\
\text { nis_murid = 'nis_murid' OR } \\
\text { nama_murid = 'nama_murid' OR } \\
\text { jenis_kelamin = 'jenis_kelamin' OR } \\
\text { tempat_lahir = 'tempat_lahir' OR } \\
\text { tanggal_lahir = 'tanggal_lahir' OR } \\
\text { gol_darah = 'gol_darah' OR alamat } \\
\text { = 'alamat' OR nama_orang_tua = } \\
\text { 'nama_orang_tua' }\end{array}$ \\
\hline $\begin{array}{l}\text { Mengubah data } \\
\text { kelas }\end{array}$ & $\begin{array}{l}\text { UPDATE kelas SET id_kelas = } \\
\text { 'id_kelas' WHERE nama_kelas = } \\
\text { 'nama_kelas' OR robel = 'robel' }\end{array}$ \\
\hline
\end{tabular}

\begin{tabular}{|c|c|}
\hline $\begin{array}{l}\text { Mengubah mata } \\
\text { pelajaran }\end{array}$ & $\begin{array}{l}\text { UPDATE mata_pelajaran SET } \\
\text { id_mata_pelajaran = } \\
\text { 'id_mata_pelajaran WHERE } \\
\text { nama_pelajaran = 'nama_pelajaran' } \\
\text { OR hari = 'hari' OR jam_masuk = } \\
\text { 'jam_masuk' OR jam_keluar = } \\
\text { 'jam_keluar' }\end{array}$ \\
\hline $\begin{array}{l}\text { Mengubah nilai } \\
\text { murid }\end{array}$ & $\begin{array}{l}\text { UPDATE nilai SET id_nilai = } \\
\text { 'id_nilai' WHERE id_user_guru = } \\
\text { 'id_user_guru' OR } \\
\text { id_mata_pelajaran = } \\
\text { 'id_mata_pelajaran' OR } \\
\text { nama_murid = 'nama_murid' OR } \\
\text { PTS_1 = 'PTS_1' OR PAS_1 = } \\
\text { 'PAS_1' OR PTS_2 = 'PTS_2' OR } \\
\text { PAS_2 = 'PAS_2' OR PAT = 'PAT' } \\
\text { OR rata_rata = 'rata_rata' OR } \\
\text { tanggal_input = 'tanggal_input' OR } \\
\text { tanggal_update = 'tanggal_update' }\end{array}$ \\
\hline $\begin{array}{l}\text { Mengubah Prestasi } \\
\text { murid }\end{array}$ & $\begin{array}{l}\text { UPDATE prestasi SET id_prestasi } \\
\text { = 'id_prestasi' WHERE } \\
\text { id_user_guru = 'id_user_guru' OR } \\
\text { nama_murid = 'nama_murid' OR } \\
\text { kelas = 'kelas' OR rombel = } \\
\text { 'rombel' OR laporan_prestasi = } \\
\text { 'laporan_prestasi' OR } \\
\text { tanggal_prestasi = } \\
\text { 'tanggal_prestasi' OR tanggal_input } \\
\text { = 'tanggal_input' OR } \\
\text { tanggal_update = 'tanggal_update' }\end{array}$ \\
\hline $\begin{array}{l}\text { Mengubah data } \\
\text { Pesan Murid }\end{array}$ & $\begin{array}{l}\text { UPDATE pesan SET id_pesan = } \\
\text { 'id_pesan' WHERE id_user_guru = } \\
\text { 'id_user_guru' OR id_murid = } \\
\text { 'id_murid' OR subjek_pesan = } \\
\text { 'subjek_pesan' OR isi_pesan = } \\
\text { 'isi_pesan' OR status_pesan = } \\
\text { 'status_pesan' OR tanggal_input = } \\
\text { 'tanggal_input' OR tanggal_update } \\
=\text { 'tanggal_update' }\end{array}$ \\
\hline $\begin{array}{l}\text { Mengubah data } \\
\text { Kasus Murid }\end{array}$ & $\begin{array}{l}\text { UPDATE kasus SET id_kasus = } \\
\text { 'id_kasus' WHERE id_user_guru = } \\
\text { 'id_user_guru' OR nama_murid = } \\
\text { 'nama_murid' OR kelas = 'kelas' } \\
\text { OR rombel = 'rombel' OR } \\
\text { laporan_kasus = 'laporan_kasus' } \\
\text { OR tanggal_kasus = } \\
\text { 'tanggal_kasus' OR tanggal_input = } \\
\text { 'tanggal_input' OR tanggal_update } \\
\text { = 'tanggal_update' }\end{array}$ \\
\hline
\end{tabular}

\section{H. Hasil Pengujian Aplikasi}

Pengujian aplikasi ini menggunakan metode pengujian Black Box. Black Box Testing berfokus pada spesifikasi fungsional dari perangkat lunak. Tester dapat mendefinisikan kumpulan kondisi input dan melakukan pengetesan pada spesifikasi fungsional program.

Hasil pengujian menunjukkan bahwa fitur-fitur yang dikembangkan sudah berjalan dengan baik. Setelah hasil pengujian aplikasi dalam tahapan pengembangan berjalan dengan baik, tahapan selanjutnya adalah tahapan implementasi, akan tetapi pada penelitian ini belum dilakukan tahapan implementasi dari aplikasi yang dibangun, karena 
terkendala masalah pandemi yang sedang terjadi di Indonesia.

\section{SIMPULAN}

Berdasarkan hasil penelitian ini, maka peneliti dapat mengambil kesimpulan bahwa:

1. Dalam membangun aplikasi penghubung guru dan orang tua berbasis web ini penulis menggunakan metode waterfall. Lalu dilanjutkan dengan identifikasi permasalahan menggunakan metode analisa PIECES sebagai dasar untuk memperoleh pokok-pokok permasalahan yang lebih spesifik sehingga orang tua mendapat informasi monitoring cepat sampai karena orang tua dapat melihat dan mengakses dimanapun.

2. Aplikasi ini dapat memberi informasi nilai murid, kasus murid, dan prestasi murid ke orang tua.

3. Aplikasi ini dapat memudahkan orang tua yang sibuk untuk dapat melihat dan mengakses dimanapun.

Sedangkan saran yang penulis bisa tambahkan pada penelitian ini adalah sebagai berikut:

1. Menambah fitur notifikasi saat ada pemberitahuan nilai, kasus, dan prestasi murid terbaru agar orang tua langsung melihatnya.

2. Mengembangkan aplikasi menjadi mobile IOS dan mobile Android sehingga lebih mudah diakses orang tua di handphone.

3. Untuk menu pesan bisa dikembangkan dengan menggunakan live chat agar guru dan orang tua lebih mudah berkomunikasi.

\section{DAFTAR PUSTAKA}

[1] H. Firmansyah dan B. Siswanto, "Aplikasi Buku Penghubung SD Ar-Rafi Berbasis Web Application Integrated with book $\mathrm{SD} \mathrm{Ar}$ - Rafi Web Based," e-Proceeding of Applied Science, vol. 3, no. 1, hal. 87-111, 2017.

[2] F. D. Andani, "Pengembangan Buku Penghubung Aktivitas Belajar Siswa Untuk Meningkatkan Prosentase Ketuntasan Belajar Program Remedial Di Mi Miftahul Ulum Pandanarum Mojokerto," Tesis, 2018.

[3] E. H. Budiarto, R. A. Yuana, dan D. Maryono, "Pembuatan Aplikasi Web Berbasis Sms Sebagai Media Penyalur Informasi Dan Komunikasi Antara Sekolah Dengan Orang Tua Siswa," Jurnal Ilmiah Pendidikan Teknik dan Kejuruan, vol. 10, no. 1, 2017.

[4] S. Salamun, "Sistem Monitoring Nilai Siswa Berbasis Android," Rabit: Jurnal Teknologi dan Sistem Informasi Univrab, vol. 2, no. 2, hal. 210-219, 2017.

[5] M. Rahmani, Haryono, dan E. Purwanti, "Pengembangan Media Komunikasi Buku Penghubung Berbasis SMS Gateway dan Mobile Web," Innovative Journal of Curriculum and Educational Technology, vol. 6, no. 2, hal. 72-78, 2017.

[6] C. A. Wagiu dan Y. Palopak, "Perancangan Hybrid Mobile Application Penghubung Orang tua dan Guru pada Sekolah Taman Kanak-Kanak Design of Hybrid Mobile Application for Parents and Teachers in Kindergarten Schools," Jurnal TeIKa, hal. 79-86, 2019.
[7] S. Sahara, "Metode Waterfall Sistem Informasi Akademik dengan Konsep Pemrograman Terstruktur pada SMP Gala Juara Bekasi,” Jurnal Sistem Informasi Stmik Antar Bangsa, vol. VII, no. 1, hal. 15-20, 2018.

[8] M. I. Hapsari dan A. Wahab, "PERMINTAAN PENGISIAN BAHAN BAKAR GENERATOR SET ( STUDI KASUS : PT . ABC )," hal. 94-98, 2019.

[9] Juansyah dan Mayasari, "Rancang Bangun Aplikasi Buku Kerjasama SDIT An-Nuriyah Sekayu" Jurnal Teknolog Informasi dan Komputer Politeknik Sekayu, Volume 10, No. 1, Januari-Juni 2020, h.20-28

[10] M.F. Ismail, A.D. Herlambang, S.A. Wicaksono, "Pengembangan Aplikasi Berbasis Android Untuk Monitoring Hasil Belajar Siswa SMK Negeri 3 Malang Oleh Orang Tua", Jurnal Pengembangan Teknologi Informasi dan Ilmu Komputer, Vol. 3, No. 10, Oktober 2019, hlm. 1024110248.

[11] H. Utari, Y.S. Triana, "Sistem Informasi Monitoring Siswa Menggunkana SMS Gateway", Jurnal Rekaya Sistem dan Teknologi Informasi, Vol. 3 No. 3 (2019) 328-335.

[12] S.I. Darmawanti, H. Noprisson, "Analisa dan Perancangan Aplikasi Monpelsis Untuk Monitoring Pelanggaran Siswa (Studi Kasus: SMK Satria Jakarta)", Jurnal Sistem Informasi dan e-Bisnis, Volume xx, Issue x, Desember 2018.

[13] R.S. Pressman, Software Engineering: A Practitioner's Approach, Seventh Edition. McGraw-Hill New York, 2010.

[14] C. Fisher et al., Introduction to Information Quality. Bloomington-USA: Author House, 2011. 